\title{
A patient's diary: episode 24 - From the electronic portfolio of Dr Sally T Greengage
}

\section{Personal Development Plan \\ Objective 1: A case study from general practice.}

Why have I chosen this objective for my plan? The uncertainties of general practice continue to puzzle me. Some of the patients are extremely difficult to diagnose. It is even more difficult to satisfy their needs and make them happy. Furthermore there is often a conflict between these two goals. I decided that by studying the most difficult patient in the practice in depth I would be able to learn more about not only his individual case but the whole nature of general practice.

Which patient have I chosen? I have chosen Mr Geoffrey Norman Gland (age: 55 years).

How will I go about putting my learning plan in to action? I shall study all the patient's records and summarise his history, diagnoses, investigation results, and episodes of treatment in secondary care. I shall look at the ways in which psychological and cultural factors may have had an impact on his health and health beliefs. I shall record his current narrative for analysis using grounded theory.

I shall explore his various illness beliefs and see if any of them has any 'scientific' substance. Have steps been taken to protect him from the risk factors to which he may be exposed?

I shall look at ways in which the practice and the profession may have failed to understand and meet his needs, bearing in mind current theory and best practice in the areas of somatisation, personality disorder, communications skills, narratology, and patient-centred medicine. I shall consider whether we have sufficiently explored his mind for hidden agenda material. In considering his symptom presentations, have we sufficiently valued his own contribution? (NB: Answer probably yes to both).

I shall note the effects that the patient's emotions inevitably have on the feelings of myself and the other doctors, nurses, and reception staff. Does he make us feel guilty as well as angry?

I shall present him at my half-day release Balint group.

At what date do I expect to achieve my objective? At the end of my specialist training. How will I know that I have achieved my objective? I shall be able to understand $\mathrm{Mr}$
Gland's mental processes better including his negative thoughts about himself.

- I will have diagnosed any hitherto unrecognised pathologies in his various systems and organs including the liver, pancreas, kidneys, eyes, and ears.

- I will have identified all risk factors operating in Mr Gland, persuaded him to adjust his life-style where appropriate and treated all abnormal parameters to target.

- I shall have carried out or arranged to be carried out any relevant psychological treatments with a view to empowering him to deal with anxiety, hypochondriasis, and other unrealistic and unhelpful beliefs.

- I shall feel less frustrated, less guilty, and more empathetic to Mr Gland and more on top of my game.

\section{Notes for case study}

Background. Geoffrey Norman Gland (known as Norman) is a 55-year-old white male. He was born in Basingstoke, where his father ran a small general store and his mother was a primary school teacher. He was the eldest child and had two sisters. He was educated at a Grammar School to GCSE standard but did not do A levels (reason unknown). However he is keen to acquire knowledge (particularly about health-related topics) and has completed several extramural courses at the Civic University.

After a number of clerical jobs he was taken on by Potters' Plastics, a local firm in which he rose to his present position as chief supervisor of production. He is married to Hilda (née Thornhill) who is a retired secretary and housewife. They have one married daughter (Sheila) and one grandson. The couple own their own semidetached house in a pleasant suburban neighbourhood.

Medical history. The early notes are missing. Possibly they did not survive the transfer to computerised records, although one of the doctors suspects that $\mathrm{Mr}$ Gland may have misappropriated them.

For the last 3 years he has complained constantly of abdominal pain and discomfort: probably irritable bowel syndrome. Also various unusual subjective sensations; giddiness; floating feelings.

In the last year he has had:

- Acute appendicitis (treated surgically without complications).

- Minor vitreous detachment affecting both eyes.

- Recurrent nose bleeds.

- Testicular pain (unknown cause).

- Calf pain (Possible Baker's Cyst. Deep vein thrombosis not totally excluded).

- Angioneurotic oedema.

Psychological symptoms. Chronic anxiety with panic attacks. Intermittent depression: usually when we fail to diagnose one of his presumed disorders. Unrealistic beliefs of a hypocondriacal nature approaching delusional intensity: that his liver is diseased, his biliary tree is obstructed; his pancreas is disordered, he has pulmonary tuberculosis (did we do a chest X-ray?), he has retinal detachment (did he ever get that appointment for the eye clinic?). A naive belief in alternative treatments of any kind associated with a scepticism about conventional medicine.

All this results in Frequent Attending (itself a pathological phenomenon). Mr Gland has an average of two appointments a week at the surgery with one doctor or another. $\mathrm{He}$ has become worryingly dependent on the GPs, particularly Dr Phillips about whom I suspect he has fantasies although he has never stalked her (if we discount the episode in the supermarket).

Why do I get so fed up with him? In fact I quite like him. He reminds me a bit of my Dad. Oh dear, is this why I have problems with him? No, can't be, because everyone has problems with him. $\mathrm{He}$ is so persistent about his liver and so on, in spite of the fact that we have done numerous scans, and bloods and even referred him to Dr Portal in the Liver Unit at the New Hospital without anybody finding anything wrong.

So we tell him his liver is normal but he doesn't believe us. He's looked it up on the internet and he thinks he knows better. Well, I'm not all that experienced and it's always worrying that maybe there is something wrong or if there isn't now there will be. And then there was that appendix that poor $\mathrm{Dr}$ Teacher missed although it was a very difficult one. Then of course if you play wolf all the time, what can you expect? And what sort of a life do those two (Norman and Hilda) live in Chestnut Avenue? Do they ever go anywhere or do anything? Should they 


\section{Learning difficulties scandal}

meet more people, join clubs? Is it really that he has nothing else to think about? The thing that gets me frustrated is that I feel we really should be able to help him.

How would I define his underlying diagnosis? He basically has a psychological or personality disorder with anxiety, obsessional features and a strong somatising tendency underpinned by strong cultural core values.

My learning needs and how I shall meet them.

1. I need to search the literature for papers on somatisation and hypochondriasis.

2. I will find a psychologist who specialises in these disorders and get some advice.

3. I will go on a course to learn cognitive behavioural and problem-solving therapies. (Must apply for study leave now).

What Dr Teacher said in our tutorial. Dr Teacher has known Norman Gland for many years. He admits to finding him trying at times but does not feel that we have failed him as a practice, which is interesting. He feels that Mr Gland is basically unlikely to achieve insight into his mind-sets or to alter his health-seeking behaviours despite the anxiety they cause him. $\mathrm{He}$ agrees that antidepressants are unlikely to be helpful, (they have been tried on occasions but $\mathrm{Mr}$ Gland never takes them for more than a week). He thinks that people like Mr Gland rely on their GP practices to help them survive 'the heartache and the thousand natural shocks the flesh is heir to'. We just have to be supportive and kind and indulge his whims (although not to the extent of breaching prescribing or referring guidelines). I said I thought this was rather a pessimistic view and he said not at all, it's realistic and it's the way the human condition is.

Some people just find it very hard to bear without a lot of help. And (he went on) when they share their symptoms with us we inevitably experience some of the feelings which they are going through. This puts us under quite a bit of strain, but it's part of our job. No one else will do it. I pointed out that we are also here (mainly?) to diagnose and treat real diseases and to prevent thousands of premature deaths by attention to diabetic control and risk factors and empowering people to change their lifestyles ...

I must have run on a bit and lost the thread but he just smiled and said: yes you are right, we have to do all that too. And I do think the CBT is a good idea. You must definitely go on that course.

This is the final instalment in the Norman Gland series. We are very grateful to John Salinsky for providing these extracts.
Last month's primary care scandal was the news that overpaid GPs are to be paid even more to provide annual health checks for people with learning difficulties. ${ }^{1}$ Press reports carried familiar themes. Although it is now universally accepted that the NHS should be administered according to the principles of the capitalist market, it is regarded as a disgrace that doctors' pay should rise in response to an increase in demand for their services. It is apparently even more offensive to public sensibilities that GPs should expect to be remunerated for an increased burden of work at a rate comparable with that received by a plumber.

The real scandal obscured by these reports is that the healthcare needs of people with learning difficulties have become the focus of political posturing and token gestures. Health secretary Alan Johnson has instructed the NHS to make improving health care for people with learning difficulties a priority following an official inquiry into a report published by Mencap in 2007. ${ }^{2}$ Death By Indifference presents six 'shocking and tragic' cases in which the deaths of people with learning difficulties are attributed to professional 'ignorance and indifference' resulting from 'institutional discrimination' in the NHS.

Here I should declare an interest. As the parent of a boy with autism and severe learning difficulties, I have often found it difficult to work out whether his challenging behaviours are a response to some change of routine or emotional upset or indicate that he is suffering from some sort of organic illness. As a doctor, I have great sympathy for other health professionals who have tried on various occasions to identify the cause of his distress, not least because I am only too well aware of the sort of pressures they work under in busy surgeries and hospitals.

As a GP, I have also some experience of the difficulties of managing the health problems of people with learning difficulties, notably in grappling with the challenges of diabetes, a not uncommon factor in premature death. Although, as both a parent and as a doctor, I have encountered good practice and bad practice, the account of systematic abuse and ill-treatment of people with learning difficulties presented in the Mencap report - and endorsed by the government bears no relation to my experience.

Mencap's model - the 1999 Macpherson inquiry into the death of Stephen Lawrence which identified 'institutional racism' within the metropolitan police force - is of dubious validity in relation to ethnic minorities. It is of even less value in relation to people with learning difficulties, who are treated as a homogenous category when one of the key challenges is their diversity.

The cases in Death By Indifference appear to have been selected to legitimise the authors' prejudices: it would be easy to make similar allegations of poor practice in relation to older people or the homeless, or any other relatively deprived section of society. Just as the Macpherson inquiry has proved popular with politicians and senior management, the concept of 'institutional discrimination' appeals to health service chiefs and the burgeoning disability bureaucracy. It allows those at the top to evade responsibility while shifting blame to frontline workers, and provides a vehicle for enhancing managerial authority.

Mencap's key recommendations are to provide more training for GPs - some activists demand that 'disability equality training' should be mandatory - and annual health checks for people with learning difficulties. Although training will provide salaries for disability activists and consultants, it will do nothing to improve primary care for people with disabilities unless GPs get more time to deal with their problems. Where is the evidence that annual health checks are of any value to people with learning disabilities?

\section{REFERENCES}

1. Brindle D. GPs get $£ 100$ for checks on people with learning difficulties. Guardian 2008

http://www.guardian.co.uk/society/2008/nov/04/n hs-bma-mencap-jonathan-michael (accessed 17 Nov 2008).

2. Mencap. Death by indifference. London: Mencap, 2007.

DOI: 10.3399/bjgp08X376384 